\title{
De herdenking van honderd jaar Eerste Wereldoorlog in België: de Federale Republiek Duitsland en de reconstructieve ethiek
}

Les commémorations du Centenaire de la Première Guerre mondiale en Belgique: La République fédérale d'Allemagne et l'éthique reconstructive The commemoration of the First World War centenary in Belgium: the German federal republic and reconstructive ethics

Geneviève Warland, Laurence van Ypersele et Valérie Rosoux

\section{(2) OpenEdition}

\section{Journals}

Édition électronique

URL : http://journals.openedition.org/temoigner/1414

DOI : 10.4000/temoigner.1414

ISSN : 2506-6390

Éditeur :

Éditions du Centre d'études et de documentation Mémoire d'Auschwitz, Éditions Kimé

Édition imprimée

Date de publication : 31 décembre 2014

Pagination : 188-191

ISBN : 978-2-84174-688-0

ISSN : 2031-4183

Référence électronique

Geneviève Warland, Laurence van Ypersele en Valérie Rosoux, « De herdenking van honderd jaar Eerste Wereldoorlog in België: de Federale Republiek Duitsland en de reconstructieve ethiek », Témoigner. Entre histoire et mémoire [Online], 119 | 2014, Online op 01 janvier 2016, geraadpleegd op 23 octobre 2020. URL : http://journals.openedition.org/temoigner/1414 ; DOI : https://doi.org/10.4000/ temoigner. 1414 


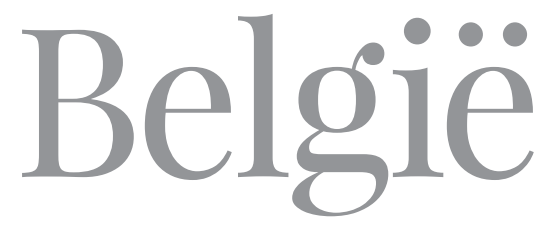

A F L E V E R I N G 1

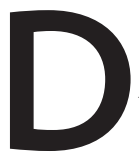

it is het eerste nummer van Getuigen waarin ons herinneringslabo 'België-Belgique' verschijnt. In deze rubriek willen we een overzicht bieden van de talrijke studies die bestaan over herinnering in een Belgische context, of die werden uitgevoerd door onderzoekers binnen Belgische academische instellingen. Het onderwerp van dit labo is dus niet beperkt tot collectieve herinneringspatronen over België of de geschiedenis van het land, hoewel dat uiteraard onze belangrijkste focus blijft.

Dit eerste luik is gewijd aan de bijdrage van Duitsland aan de herdenking van de Eerste Wereldoorlog in België, maar ook aan de aandacht die de Belgische media schenken aan de aanwezigheid van Duitse vertegenwoordigers tijdens officiële plechtigheden. Het is niet onlogisch dat we voor ons eerste labo inspelen op de actualiteit, en dan meer bepaald die van de Grote Oorlog. Ondanks de vele evenementen die vandaag plaatsvinden, stellen we immers vast dat een aantal essentiële kwesties onderbelicht blijven. Het herinneringslabo wil een plek zijn waar die vragen behandeld kunnen worden.

In het tweede deel zullen we dezelfde piste bewandelen en inzoomen op de populariteit van hedendaagse literatuur over 14-18, zowel in het Franse als het Nederlandse taalgebied. In Frankrijk was de fascinatie voor de oorlog enkele jaren geleden al te merken in 14 van Jean Echenoz of, recenter, Au revoir là-haut/Tot ziens daarboven van Pierre Lemaître. Nu lijkt die trend zich ook door te zetten in de Vlaamse literatuur: Stefan Hertmans' Oorlog en terpentijn was een enorm succes, maar laten we ook niet De dood van een soldaat van Johanna Spaey vergeten, Godenslaap van Erwin Mortier en Post voor mevrouw Bromley van Stefan Brijs. Wat is het verband tussen literatuur en realiteit, authenticiteit en imitatie, herinneren en vergeten?

In 2015 zal het honderd jaar geleden zijn dat de Armeense genocide plaatsvond. We wijden het labo dan aan herdenkingsinitiatieven in België en aan de relatie met de Turkse gemeenschap. We staan ook stil bij de herdenking van de Slag bij Waterloo, tweehonderd jaar geleden. Verder is er ruimte voor een vergelijkende studie van tentoonstellingen over de Eerste Wereldoorlog. Grote projecten (bijvoorbeeld in het Brusselse Legermuseum of het station van Luik-Guillemins) leggen vaak een heel andere klemtoon dan lokale tentoonstellingen in Vlaamse, Waalse of Brusselse gemeenten, waar familieherinneringen centraal staan. De dynamiek tussen persoonlijke en nationale verhalen vormt het onderwerp van een lopend onderzoeksproject rond intergenerationele herinneringen over de Tweede Wereldoorlog in België. Uit de eerste resultaten blijkt dat er nauwelijks nog sprake is van herinneringsoverdracht, en dat het probleem zich voornamelijk situeert bij persoonlijke verhalen in de derde generatie. We moeten ons dus dringend vragen stellen over de manier waarop grote historische gebeurtenissen in België van de ene generatie op de andere worden doorgegeven.

Olivier Luminet (Vertaling: Anneleen Spiessens) 


labo
Wit herinneringslabo
uitgroeit tot een
ruimte voor nieuwe
ideeën en dialoog.
Dankzij onze ervaring
in interdisciplinair
onderzoek hebben
we al vaak dergelijke
projecten kunnen
opzetten. Het is onze
bedoeling in deze lijn
verder te werken en
ons onderzoek aan een
breder publiek voor te
stellen, maar we willen
ook anderen de kans
bieden om deel te
nemen aan het debat.
We staan daarom open
voor uw bijdragen,
voorstellen en reacties.
Laten we ons samen
verdiepen in het unieke
herinneringslabo dat
België is!

(1) Interview met Christian Laporte, La Libre Belgique, 26 augustus 2014, 53.

(2) De toespraken van de Duitse Bondspresident op 4 augustus 2014 in Luik en Leuven zijn beschikbaar in het Duits, Frans, Engels en/of Nederlands op zijn webpagina: http://www. bundespraesident.de/DE/ Bundespraesident-JoachimGauck/Reden-und-Interviews. Verder citeren we in dit artikel uit de toespraken van de Duitse Ambassadeur in het Koninkrijk België en van de Duitse regeringsvertegenwoordiger voor de mensenrechten op 28 februari 2013. We verkregen deze teksten via de Culturele dienst van de Duitse Ambassade in Brussel.

\section{DE HERDENKING VAN HONDERD JAAR EERSTE WERELDOORLOG IN BELGIË. DE FEDERALE REPUBLIEK DUITSLAND EN DE RECONSTRUCTIEVE ETHIEK}

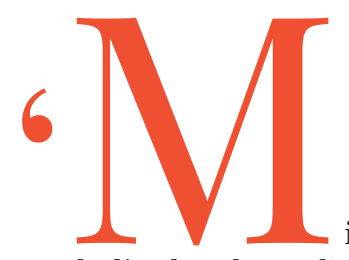

ijn land is nog steeds diep beschaamd', kopte La Libre Belgique boven een interview met de Duitse ambassadeur in België, Eckart Cuntz. ${ }^{1}$ Schaamte en spijt weerklinken in de toespraken van de officiële vertegenwoordigers van Duitsland tijdens herdenkingsplechtigheden voor de Eerste Wereldoorlog in België. Bondspresident Joachim Gauck had een goed gevuld programma op maandag 4 augustus 2014: 's ochtends nam hij deel aan de plechtigheid bij het Monument voor de Intergeallieerden in Cointe (Luik) in aanwezigheid van Koning Filip, Koningin Mathilde en een twintigtal staatshoofden en afgevaardigden die samen 83 landen in het conflict vertegenwoordigden. In de namiddag hield hij een toespraak aan de Katholieke Universiteit van Leuven en's avonds woonde hij een ceremonie bij op het Duits-Britse kerkhof Saint-Symphorien in Bergen. De Duitse ambassadeur, Eckart Cuntz, deed niet onder voor zijn collega. Enkele maanden geleden begon hij aan zijn herinneringsmarathon en liet zich opmerken tijdens zowat alle herdenkingen voor Belgische soldaten en burgers die honderd jaar geleden het leven lieten. Dat bracht hem naar verschillende martelaarssteden in het zuiden (Andenne, Dinant, Taines, Visé, ...) en het noorden van het land (Aarschot, Dendermonde, Leuven, ...).

We ontwaren drie belangrijke thema's in de toespraken van Duitse vertegenwoordigers op Belgisch grondgebied. ${ }^{2}$ Allereerst erkennen ze volledig de Duitse verantwoordelijkheid voor de misdaden die in België zijn gepleegd aan het begin van de oorlog: schending van de neutraliteit, moord op burgers, brandstichting, plundering. 'De verschrikkelijke "Grote Oorlog”, zo betoogt Joachim Gauck op 4 augustus in Luik, 'zou de eerste van twee wereld- 


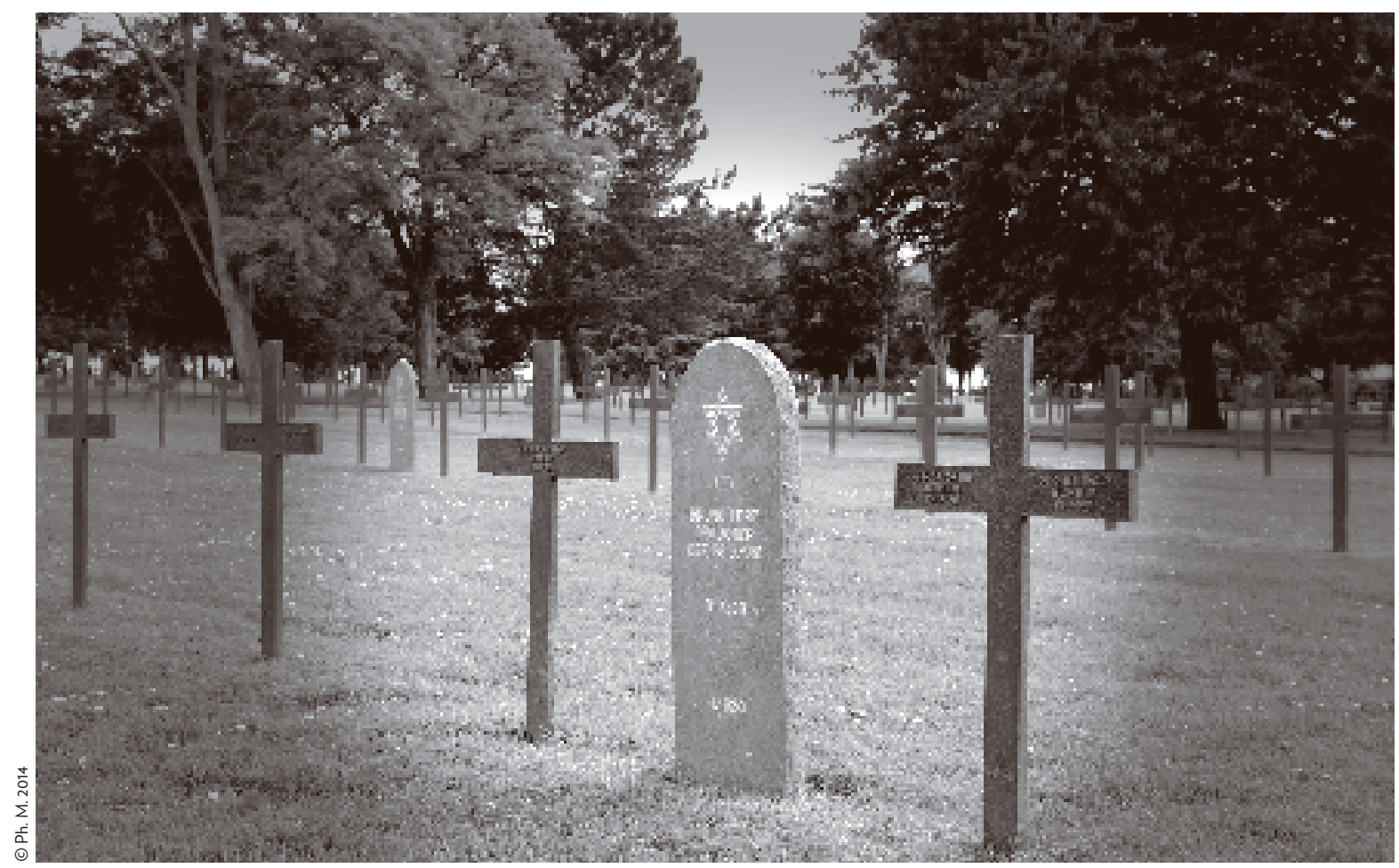

oorlogen zijn. Deze oorlog begon in West-Europa met de door niets te rechtvaardigen inval van Duitsland in het neutrale België.' Hij verwijst ook naar de 'beschamende' oproep van Duitse intellectuelen die in 1914 stelden dat 'de misdaden tegen land en mensen, ook en juist de aanvallen op de cultuur, terecht en zelfs noodzakelijk waren'. Op 15 augustus 2014 onderstreept de Duitse ambassadeur in Dinant hoe 'belangrijk het is dat wij de moordpartijen en de misdaden erkennen die toen zijn gepleegd'. Op 28 februari 2013 sprak de Duitse regeringsvertegenwoordiger voor de mensenrechten een rede uit bij de inhuldiging van een herdenkingsplaat voor burgerslachtoffers in de provincie Luxemburg. Hij eerde de '786 burgers uit verschillende Luxemburgse gemeenten [die] stierven in de eerste dagen van de oorlog. De verant- woordelijkheid voor hun dood berust bij de Duitse troepen.'

Het tweede element dat steeds terugkomt is de spijtbetuiging, waarin we in het algemeen gevoelens van schaamte, verdriet en ontsteltenis kunnen bespeuren (zoals in de rede van ambassadeur Cuntz op 28 februari 2013). Er worden excuses uitgesproken, de slachtoffers worden geëerd en iedereen komt samen om 'de doden te herdenken'. ${ }^{3}$

Het gaat vaak niet alleen over de eerste en bijzonder brutale invasie van het Belgische grondgebied, maar ook over de tweede in mei 1940. Dat zien we bijvoorbeeld in de toespraak van de Bondspresident in Leuven. Zijn discours heeft echter een positieve benadering: in plaats van zich uit te putten in verontschuldigingen, drukt Gauck zijn dank uit aan de universiteit van Leuven, die •••
_ Graf van Bruno Herz, een Duitse Jood die sneuvelde voor Duitsland op 28 september 1918. Duits kerkhof van Neuville-SaintVaast, bij Arras in de NordPas-de-Calais.

(3) De excuses komen van de ambassadeur en de regeringsvertegenwoordiger; Bondspresident Gauck benadrukt in Leuven het belang van de 'dodenherdenking' terwijl de regeringsvertegenwoordiger vooral een eerbetoon wil brengen aan de slachtoffers. 
(4) In het algemeen is er in Nederlandstalige kranten minder aandacht voor de herdenking van de invasie in augustus 1914 (we bestudeerden de edities van het weekend van 2-3 augustus, maandag 4 en dinsdag 5 augustus 2014). Enkel de Franstalige pers verslaat het bezoek van de Koning aan Thimister, waar de eerste Belgische soldaat is gesneuveld, en aan het Fort van Loncin op 3 augustus. Kranten in de beide landsdelen wijden wel verschillende pagina's aan de eeuwherdenking op maandag 4 augustus. Ze citeren ook de Duitse Bondspresident en prijzen diens ingetogenheid, hoewel die verschillend wordt geïnterpreteerd door La Libre Belgique en Het Laatste Nieuws: de Nederlandstalige krant ziet in die houding immers een verontschuldiging - de Franstalige krant vermijdt juist het woord 'excuses' - en citeert Gauck wanneer hij verwijst naar 'gevoelens van superioriteit en extreem nationaal egoïsme' (Het Laatste Nieuws, dinsdag 5 augustus, 4)

(5) Toespraak van Ambassadeur Dr. Eckart Cuntz tijdens zijn bezoek aan Dinant op vrijdag 15 augustus 2014. De Frans-

Duitse vriendschapsband werd aangehaald tijdens verschillende evenementen. Zo legden de Duitse en Franse ambassadeurs op 15 augustus 2014 gezamenlijk een bloemenkrans neer tijdens de ceremonie in Dinant ter nagedachtenis van de burgerslachtoffers. Ze waren ook vaak samen aanwezig op plechtigheden in 2013.

(6) Egyptoloog en cultuurhistoricus Jan Assmann maakte voor het eerst het onderscheid tussen culturele en communicatieve herinnering in zijn boek Das kulturelle Gedächtnis (2013).
- meteen na de oorlogwerk heeft gemaakt van de Belgisch-Duitse verzoening en de wederopbouw van Europa.

Die Europese wederopbouw, een garantie voor vrede en veiligheid tussen de voormalige opposanten, vormt de rode draad in Gaucks toespraken. In Luik benadrukt hij dat 'in Europa thans de sterkte van het recht geldt, en niet het recht van de sterkste', een uitspraak die door vele Franstalige en Nederlandstalige kranten wordt overgenomen. ${ }^{4} \mathrm{Hij}$ voegt daaraan toe: 'Een verworvenheid die getuigt van beschaving en niet kan worden overschat, is het feit dat kleine en grote lidstaten van de Europese Unie tegenwoordig in Brussel vreedzaam gemeenschappelijke standpunten trachten te vinden en tot overeenstemming komen over een gemeenschappelijk beleid.' Ook ambassadeur Cuntz gelooft dat 'we dankzij het werk van haar grondleggers geen oorlog meer kennen in de Europese Unie"5.

De Europese Unie vormt de aanleiding om te waarschuwen voor nationalistische tendensen die honderd jaar geleden de Duitse gewelddaden inspireerden, maar die ook vandaag nog goed gedijen en talrijke conflicten voeden overal ter wereld. De uitdaging bestaat erin om je niet in slaap te laten wiegen door de vele eerbewijzen en herdenkingsplechtigheden, zo stelt Gauck aan het Monument voor de Intergeallieerden, maar om lessen te trekken uit de oorlogen en zich te verzetten tegen de schending van de mensenrechten vandaag de dag.

Wat kunnen we nu besluiten uit deze korte analyse? Klinken de woorden van de Duitse vertegenwoordigers zo gewichtig omdat honderd jaar Grote Oorlog een wissel in het herinneringsregime inluidt - de overgang van een communicatieve herinnering gebaseerd op het doorgeven van ervaringen, naar een culturele herinnering zonder 'levende' band? ${ }^{6}$ Of hebben we met de herdenkingen een koerswijziging ingezet die wijst op een meer ethische invulling van internationale relaties? Sinds een dertigtal jaren stapelen de spijtbetuigingen, excuses en symbolische verzoeningen zich immers op.

De Franse filosoof Jean-Marc Ferry zou geneigd zijn om die laatste verklaring naar voren te schuiven. Tegenwoordig wordt het verleden op een nieuwe manier ingezet in de buitenlandse politiek, zo schrijft de auteur. De toespraken van de Duitse vertegenwoordigers zijn een voorbeeld van wat hij een 'reconstructieve ethiek' (Ferry 1996) noemt: een soort van spijtbetuiging waarbij de schuldige landen het geweld tegenover de slachtoffers erkennen en de feiten ook als integraal onderdeel beschouwen van hun nationale geschiedenis. Deze redenering vinden we bijvoorbeeld terug in de toespraak die de voormalige Bondspresident Richard von Weizäcker op 8 mei 1985 hield voor de Bundestag. Naar aanleiding van de veertigste verjaardag van het einde van de Tweede Wereldoorlog verwees hij naar de verantwoordelijkheid van het Duitse volk tegenover de moorddadige waanzin van de nationaal-socialistische regering en riep hij op om de herinnering levendig te houden ('die Erinnerung wachzuhalten'). ${ }^{7}$

De reconstructieve ethiek of 'ethiek van de verantwoordelijkheid voor het verleden' (Ferry 1996, 40) bestaat volgens Ferry uit twee luiken: een intellectueel luik waarvoor kennis is vereist van het gewelddadige verleden, en een moreel luik waarin dat verleden als dusdanig wordt erkend in de publieke 
ruimte en initiatieven worden genomen tot symbolisch herstel. Hoewel de reconstructieve ethiek is gericht op de misdaden en slachtoffers in het verleden, is ze door het bijbehorende herinneringswerk toch sterk verankerd in het heden. Tot slot is er een bepaald soort van zelfbeschouwing en zelfkritiek voor nodig. In het geval van de Eerste Wereldoorlog gaan de schuldige landen op zoek naar een nieuw referentiepunt voor hun herinneringsbeleid en worden nationale herinneringen opengebroken om uiteindelijk 'zichzelf in de ander te herkennen' (Ferry 2005, 86). Laat dat nu net de visie zijn die Joachim Gauck verkondigt aan de Leuvense universiteit: hij legt daar duidelijk de nadruk op het universele leed dat de oorlog heeft veroorzaakt. Hij las dagboeknotities van soldaten aan beide zijden van het front en besluit dat zij een 'duidelijke, schokkende' boodschap brengen. 'Het lijden, de ontberingen en angsten waren overal dezelfde en maakten geen onderscheid tussen vriend en vijand. Wanneer we nu dit verleden herdenken, herdenken we ook dat het leed ondanks alle tegenstellingen een gezamenlijk leed was.'

De Duitse vertegenwoordigers stelden hun toespraken op in de geest van deze reconstructieve ethiek. Ze verwijzen naar de misdaden van het Duitse leger en nemen die op in hun nationale geschiedenis. Ze erkennen ook hun blijvende verantwoordelijkheid. Hun doel is om samen te werken aan een gedeelde geschiedenis, om een gemeenschappelijke herinnering op te bouwen aan het oorlogsgeweld en het leed dat alle mensen en volkeren trof, over de grenzen heen. Honderd jaar na de feiten wordt dat stilaan een culturele, en geen communicatieve herinnering. Een soort van morele imperatief om de vrede te bewa-

\section{De mediastilte valt misschien te verklaren door het feit dat de Belgen deze tragische gebeurtenissen wat vergeten waren en er nu plots overal en op elk moment aan herinnerd worden.}

ren en respect te tonen voor de onvervreemdbare rechten van de mens, op het Europese continent en daarbuiten. Dat is de les die Duitsland moet trekken uit haar 'rampzalige geschiedenis', om de woorden van Joachim Gauck in Luik aan te halen. Het is niet alleen een les voor Duitsland, maar voor alle staten en naties wereldwijd.

Het mag enigszins verbazen dat de toespraken zo weinig weerklank vonden in de Belgische media. Kranten, radioen tv-zenders besteedden nochtans maandenlang uitgebreid aandacht aan de gruweldaden die de Duitse troepen in augustus 1918 pleegden tegenover de Belgische burgerbevolking. Uiteraard vermeldde de pers kort de aanwezigheid van Bondspresident Gauck of ambassadeur Cuntz in de martelaarssteden - La Libre Belgique publiceerde zelfs een paginalang interview met de ambassadeur - maar analyses of uitgebreid commentaar ontbreken. Die stilte valt misschien te verklaren door het feit dat de Belgen deze tragische gebeurtenissen wat vergeten waren, en er nu plots overal en op elk moment aan herinnerd worden. Er is waarschijnlijk tijd nodig, zodat de emoties kunnen bekoelen en de Belgen dit verleden kunnen verwerken. Dan is het aan de media om zich te gaan verdiepen in de rol van Duitsland in het herinneringsdebat.

Geneviève Warland, Laurence van Ypersele en Valérie Rosoux (Vertaling: Anneleen Spiessens)
(7) Deze rede is terug te vinden op de site van de Bondspresident: http://www.bundespraesident. de/SharedDocs/Reden/DE/ Richard-von-Weizsaecker/ Reden/1985/05/19850508_Rede. html. In zijn artikel 'L'idée d'une justice reconstructive dans les relations internationales' (s.d.) geeft Ferry het voorbeeld van Jacques Chirac die in 1995 de razzia's van de Vel d'Hiv herdacht.

\section{BIBLIOGRAFIE}

- Jan Assmann, Das Kulturelle Gedächtnis. Erinnerung und politische Identität in frühen Hochkulturen, München: Beck, 2013.

- Jean-Marc Ferry, Léthique reconstructive, Parijs: Le Cerf, 1996

-, 'L'idée d'une justice reconstructive dans les relations internationales', http://users. skynet.be/sky95042/45contri. pdf (geraadpleegd 30 november 2014).

-, Europe, la voie kantienne. Essai sur l'identité postnationale, Parijs: Le Cerf, 2005. 